\title{
PRIMARY MELANOMA OF THE LEPTOMENINGES
}

\author{
BY \\ J. BOUTON \\ From the Neurosurgical Unit, South-Eastern Region, Brook Hospital, Woolwich, and \\ Lewisham Group Laboratory, Lewisham Hospital
}

(RECEIVED FOR PUBLICATION MAY 31, 1957)

Primary melanomata of meninges are rare tumours, and well-documented cases rarer still. In 1935 Akelaitis, in a comprehensive review of the literature, collected 29 cases and added one of his own. In 1949 Touraine reviewed all the reported cases of primary pigmented tumours of the meninges; the total was then 66 , an addition of only 29 cases in 14 years. Both Akelaitis and Touraine, however, express doubt as to the validity of a number of the reported cases, and Touraine accepts only 27 as being true malignant primary melanomata of the meninges. In that number are included six cases, namely, those of Pol (1905), Weimann (1923), Ehnmark and Jacobowsky (1926), Baumecker (1929), Mackay and Hurteau (1942), Foot and Zeek (1931), case 2, which are unacceptable, as pointed out later, because of the presence of extracranial tumours. Since then six more reports have appeared (Strong. 1947 ; Pautler and Gallavan, 1951 ; King, Chambers, and Garey, 1952, two cases ; and Russi, Robinson, and Nagler, 1953, two cases). Both the cases of Strong and of Pautler and Gallavan revealed extracranial tumours at necropsy, while Case 2 of Russi et al., as the authors themselves imply, does not fulfil the criteria for the diagnosis of a primary melanoma of the meninges. We thus have a total of only 24 cases in which a diagnosis of primary malignant melanoma of the meninges is considered acceptable.

The purpose of this paper is to record another case which, it is believed, is the first one to have been diagnosed in life in Great Britain.

\section{Clinical History}

A. S., a man aged 25, in August, 1955, woke up with pain in the occipital region, the back of the neck, and radiating down the spine. $\mathrm{He}$ vomited and was unsteady on his feet. At the hospital where he was admitted the only reported abnormality was in the cerebrospinal fluid, which contained 23 lymphocytes/ c.mm. and $300 \mathrm{mg}$. protein per $100 \mathrm{ml}$. He was transferred to the Regional Neurosurgical Unit.
On admission on November 2,1955 , he was con- $\overrightarrow{-}$ fused, euphoric, occasionally having hallucinationsin and unable to stand because of paroxysms of $\vec{N}$ disequilibrium. His wife reported that during the N past three months his memory had deteriorated and $\mathrm{O}$ he had become irritable. He had slight papilloedema on the left and fine tremor of the outstretched hands, 3 but otherwise no neurological signs. A lumbar puncture, performed on November 7, showed that the $\frac{\rho}{\partial}$ cerebrospinal fluid contained 28 lymphocytes/c.mm. $\vec{\rho}$ and $350 \mathrm{mg}$. protein per $100 \mathrm{ml}$. The sugar content $\stackrel{\oplus}{0}$ was $50 \mathrm{mg}$. per $100 \mathrm{ml}$. and chloride $690 \mathrm{mg}$. per ${ }^{\circ}$ $100 \mathrm{ml}$. No malignant cells could be seen. Radiographs of the skull and chest were normal. Ventriculography revealed markedly enlarged symmetrical ventricles with the aqueduct and the fourth ventricle patent. A provisional diagnosis of arachnoiditis was $\frac{2}{\mathbb{1}}$ made with a block at the tentorial level. In view of $\varrho$ his continuing deterioration it was decided to explore $\overrightarrow{\overrightarrow{0}}$ the posterior fossa.

At operation on December 13, on opening the dura the leptomeninges covering the cisterna magna and brain-stem were seen to be uniformly and densely covered with dark brown and black deposits; a biopsy was taken. The biopsy material (Fig. 1)음 showed a diffuse infiltration of the meninges by 3 . irregular groups and sheets of heavily pigmented cells. The reactions of the pigment were those of melanin. Nuclear details were mostly completely obscured by the pigment, but there were some bizarre forms and 5 binucleated cells. After operation and decompression, $D$ his symptoms temporarily abated and he was discharged home on January 4, 1956.

The diagnosis was melanosis of the leptomeninges. Or

Three days after discharge the patient was re- $N$ admitted because of retention of urine. His general condition gradually deteriorated and he died on January 16.

Necropsy.-The skin was deeply pigmented $\stackrel{\varrho}{=}$ all over, somewhat reminiscent of a suntan, but his@ ancestry was English and he had not been sunbathing. No abnormality was found except in the cerebral nervous system, and no neoplasm was found in any other viscus. There were no moles or previous opera- $\stackrel{\oplus}{\mathscr{Q}}$ tion scars of any sort. All the nails were carefully 2 examined, and no subungual melanoma was found. The eyes were taken out for microscopical examination. 


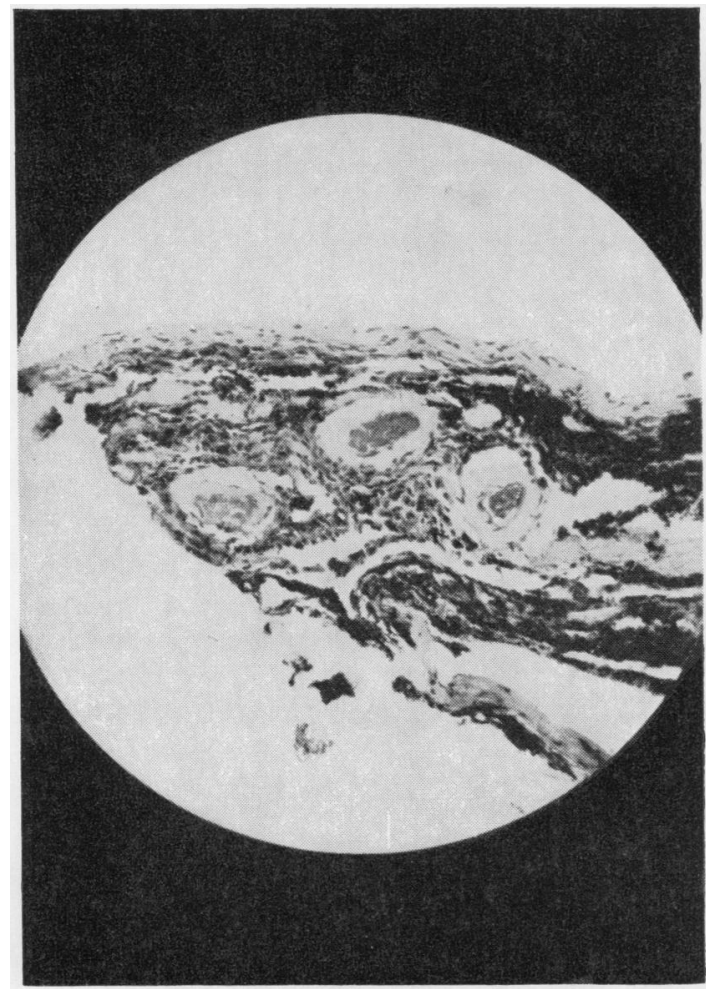

FIG. 1a.-Biopsy of leptomeninges, showing meninges infiltrated by irregularly pigmented cells. Notice tendency to perivascular distribution of pigmented cells.

Central Nervous System.--The leptomeninges covering the base of the brain and its under surface (Fig. 2) were jet black, the pigmentation being thickest in the midline stretching from the medulla to the optic nerve, obscuring the optic chiasma. Laterally the pigmentation spread out more or less symmetrically on the inferior surfaces of the cerebellum and of the temporal lobe, and tended to follow the lines of the main fissures, especially the Sylvian fissure. Anteriorly it spread along the olfactory tracts: as the pigmentation thinned out from the main mass it hecame more discrete and resolved into flat miliary nodules of about $1 \mathrm{~mm}$. in diameter. All the issuing nerves, especially the optic chiasma and nerves, were ensheathed, but apparently not invaded. As it was decided to preserve the specimen serial coronal sections were not made, but the upper surface of the parietal and occipital lobe on one side was shaved to reveal the lateral ventricle (Fig. 3). The ependyma was seen to be covered uniformly by the same miliary nodules.

The circumferential pigmentation of the brain-stem continued uninterrupted along the whole length of the spinal cord (Fig. 4) and the separate roots of the cauda equina received their separate coats. Sections of the cord at various levels again showed the pig-

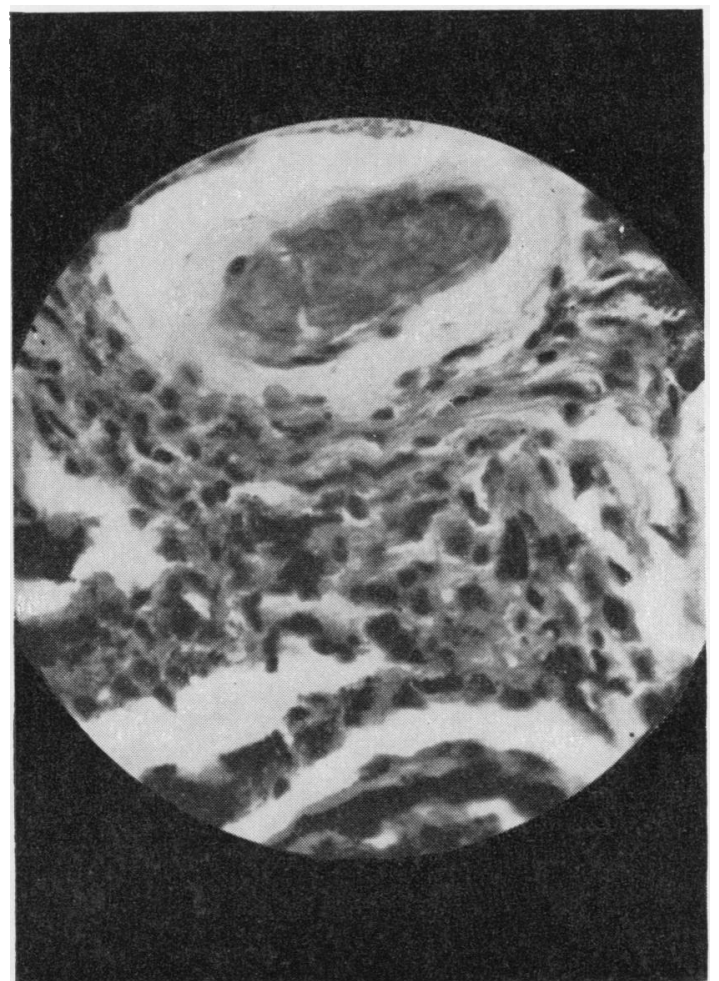

FIG. 1b.-High-power view of Fig. $1(\times 400)$ to show large bizarre cells and irregular nuclear staining.

mentation to follow the fissure, but no infiltration of the cord was apparent. The dura was normal.

Histology.-The eyes were normal. The whole of the leptomeninges was widely infiltrated by pigmented cells. The pigment gave the characteristic reactions of melanin. The arrangement of the cells was variable, but mostly they lay in loosely knit sheets with very scanty supporting stroma. In the denser areas there was a tendency to form syncytium, but otherwise the cells were distinct; perivascular cuffing was a notable feature, and indeed here and there the cells were carried into the nervous tissue substance for a short distance through the perivascular spaces, although there was no direct invasion of the nervous tissue. The cells were mostly polygonal or oval. The pigmentation was very irregular and uneven, and. where the degree of pigmentation allowed detailed microscopy, the nuclei were seen to be vesicular with a dense nuclear membrane and a well-defined nucleolus ; giant and binucleated forms were present : the degree of pigmentation sometimes did not allow differentiation from pignent-laden histiocytes, but in the lighter areas the cells were obviously neoplastic (Fig. 5).

Nerious Parenchyma.--As noted above. direct invasion was not observed, but all the spinal roots of 


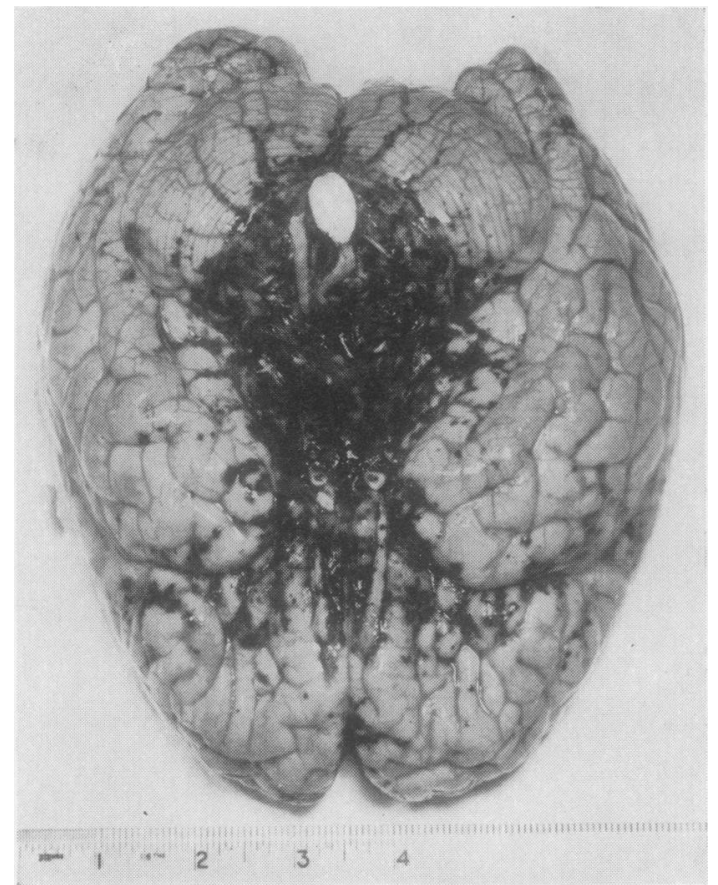

FIG. 2.-Base-of brain showing distribution of pigment.

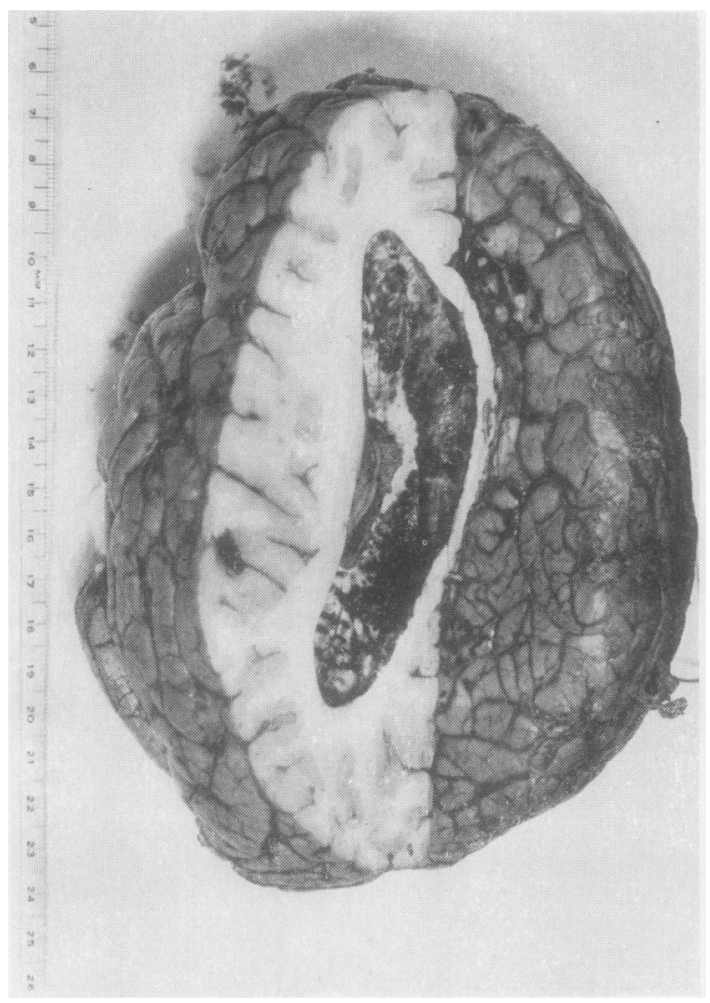

Fig. 3.-Cavity of lateral ventricle viewed from above.



FIG. 4.-Spinal cord and cauda equina. 


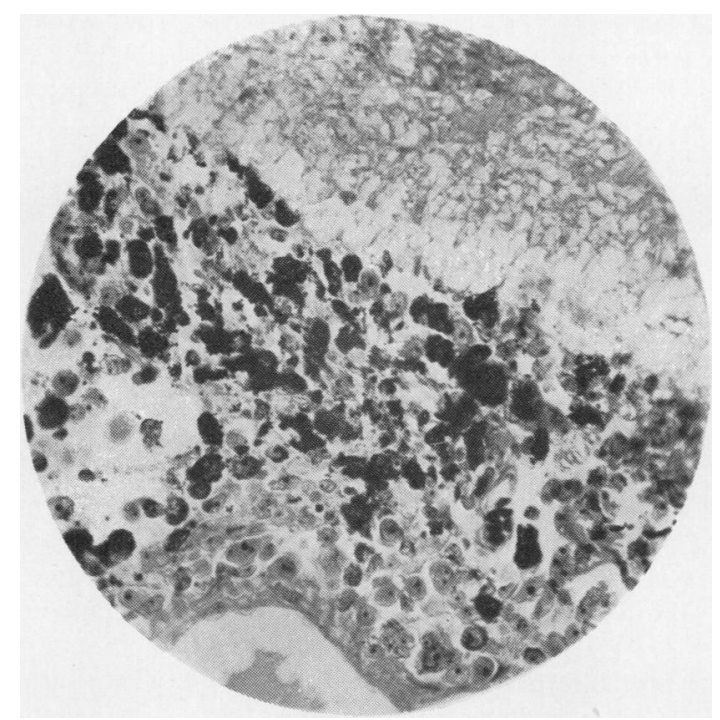

FIG. 5.-Leptomeninges covering pons $(\times 320)$ showing irregular pigmentation; lighter areas show irregularity of shape and size of cells.



FIG. 6.-Spinal nerve $(\times 80)$. The nerve bundles are closely invested in a sheath of pigmented cells following the line of the fibrous tissue septa between the fibres.

peripheral nerves were closely invested in a mantle of pigmented cells, and these also followed the fibrous tissue septa lying between the constituent fibres (Fig. 6).

Optic Chiasma.-This lay in the densest zone of pigmentation. Again no nervous invasion could be seen, but the nerve fibres were ensheathed by the neo- plastic cells, some of which had penetrated the glial coverings.

Wall of Ventricle.-A thin layer of pigmented cells lay among the ependymal cells; there was no extension into the white matter and no destruction of either ependyma or nerve cells.

The pituitary was normal.

\section{Conclusions and Comments}

There is no doubt that this case is one of primary melanosis of the leptomeninges. The question of malignancy is more difficult to evaluate. No definite evidence of invasion could be found, but the irregular proliferation of the cells, the irregularity of their pigmentation, the presence of bizarre and giant forms leave no doubt that malignant change had taken place in situ. This is further supported by a comparison with the case of Forbes and Maloney (1950). The latter resembles the present case in all its aspects and histological details, with the exception that Forbes. in addition, demonstrated direct invasion of the spinal cord in one area. It follows that malignant change can occur elsewhere along a neuraxis which is already the seat of a widespread melanosis and can occur at several places simultaneously. Multicentricity of origin must not be misinterpreted as dissemination from a primary focus.

Therefore the points which should always be considered in cases of primary meningeal melanomata are $(a)$ the diffuse melanosis, $(b)$ the absence of tumours elsewhere, and $(c)$ the associated skin pigmentation.

(a) In the majority of reported cases of melanomata there has been a diffuse infiltration of the meninges. Indeed, Winkelman, Gotten, and Silverstein (1936) consider that one of the diagnostic criteria of primary melanoma of the meninges is their diffuse involvement. King et al. (1952), however, point out that, although this may be the final situation as seen at necropsy, the early stages (as in their case 1) may be a localized tumour of the meninges, which later on disseminates along the neuraxis. Be that as it may, a strictly localized tumour, without accompanying melanosis, especially one causing destruction of bone, should arouse suspicions of a primary elsewhere or of a pigmented meningioma. Kissel, Rousseaux, Beau. Midon, and Arnould (1950) report such a case of localized "primary" melanoma of the meninges which recurred after excision, but no necropsy report was included and a large melanoma of the foot was present on which there was no histological report. Such cases warrant fuller documentation and will again be discussed. 
A more difficult problem is that of the pigmented meningioma. Ray and Foot (1940) first drew attention to the resemblance between localized "melanomas" and meningiomas, and Bakody, Hazard, and Gardner (1950) report a case where a mass, localized to $\mathrm{L} 2-\mathrm{L} 4$, was excised and diagnosed as a melanoma. Six years after the operation, as the patient was still well, the slide of the previous operation specimen was reviewed and the tumour was found to be a meningioma. In an analysis of 58 cases of melanotic tumours of the meninges, Touraine (1949) found a diffuse melanosis in 17 out of the 27 cases in which there was indubitable evidence of malignancy, either invasion of the nervous parenchyma or dissemination. The remaining 31 he regarded as simple melanosis, although recognizing two degrees of the condition, a diffuse form (melanisme) of which there were eight cases, and a more discrete form (melanose) of which there were 22 cases. It would not, therefore, be unreasonable to assume that melanosis, diffuse in the majority of cases, always precedes the development of malignancy, and must be regarded as an essential prerequisite of primary melanomata of the meninges. This would seem more plausible than to regard the melanosis as secondary dissemination as King, Chambers, and Garey (1952) suggest.

(b) Melanomata of the meninges are not as malignant as their counterpart in the skin and eyes. Visceral metastases are not found (Willis, 1948). Strong (1947), arguing against this view, quotes a case of Foot and Zeek (1931) and one of his own, in which there were widespread melanotic tumours in the skin, lymph nodes, lung, right adrenal, stomach, and cerebellum. In the presence of so many possible sites for the primary, it seems unwise-to say the least-to select the cerebellar meninges as the source of so many metastases. The case of Foot and Zeek is rejected by Willis on the same ground. Forbes goes further and suggests that all cases in which there is a history of previous operation on a skin or eye tumour should be rejected. Bakody et al. (1950) go yet further :

"A primary leptomeningeal origin cannot be accepted as such unless a careful search fails to disclose a primary malignant lesion in the eye, skin. or visceral organs, and even then the presence of intracerebral melanotic nodules could challenge an interpretation of primary origin."

These criteria seem laudable and exclude the eight cases mentioned in the introduction.

There is no doubt then that in the majority of reported cases the neoplastic process has remained localized to the meninges and the central nervous system. This behaviour, remarkably differen from the highly malignant cutaneous tumours? may have some importance histogenetically Many theories have been put forward to explain the origin of melanomata. It is beyond the scope of this report to embark upon a detailed discussion of this problem.

The majority of pathologists nowadays accepe $\vec{P}$ the view that cutaneous melanomata are epithelia $\vec{\omega}$ in origin, as shown by Dawson (1925). The opponents of that theory, in particular those who still support Masson's views that melanomata are derived from sensory nerve endings, believe that such nerve endings exist in the leptomeninges(Stoler, quoted by Akelaitis, 1935), and would beN the origin of meningeal melanomata (Foot and Zeek, 1931). Such a unified conception ignores the above-mentioned difference in behaviour? which suggests a difference in cell potentiality ans hence a difference in the cell of origin. Branched? pigmented cells are normally present in the्e meninges and described in standard textbooks ob histology (Maximow and Bloom, 1948). It seems reasonable to assume that they are the cells of origin of melanosis and melanomata of the meninges. Their own origin, whether neuro@ epithelial or mesoblastic, is more difficult to estab lish. But this controversy should have no bearing on the theories of origin of cutaneous melanomataO

(c) The most interesting feature of the condition is the associated abnormalities of pigmentation in the skin. In an analysis of 42 cases of diffuse melanosis, in which information regarding the skin was published, Touraine found that in $56 \%$ there was abnormal pigmentation of the skin and. in $26 \%$ the abnormality was severe enough tळ cause disfiguration. (By contrast, in seven cases in which localized primary melanoma of the meninges was diagnosed without associated diffus $\triangle$ melanosis of the meninges, two only had abnorma? pigmentation of the skin. These figures are addiN tional evidence that localized "melanoma" without the accompanying melanosis of the centrab nervous system is a separate entity and probabl not a primary disease of the meninges.) It iब likely that primary melanosis of the meninges part of a systematized abnormality, probably con genital, of pigment formation. However, the roles of the endocrines cannot be ignored in view of theo well-known disorder in Addison's disease.

The pituitary, too, plays a part in the control o\$ pigment production and extracts of the posteriog lobe cause an expansion of the skin melanophore in the frog. In man, the chloasma of pregnancb 
may well be attributable to pituitary hyperfunction, while victims of pituitary cachexia may develop a generalized pigmentation. In the present case, however, the endocrines were normal.

\section{Summary}

A case of primary melanosis of the leptomeninges is described, and the literature is reviewed.

The criteria for diagnosis are discussed.

It is suggested that melanosis is a form of a systematized abnormality of pigmentation.

I wish to thank Dr. W. Gibb, consultant neurosurgeon, for permission to publish this case, and Dr. I. Williams, pathologist, Brook Hospital, for permission to use material, and Dr. E. N. Allott, Director, Lewisham Group Laboratory, for assistance in the preparation of this paper.

\section{REFERENCES}

Akelaitis, A. J. E. (1935). Amer. J. Path., 11, 591.

Bakody, J. T., Hazard, J. B., and Gardner, W. J. (1950). Cleveland Clin. Quart., 17, 89.

Baumecker, H. (1929). Frankfurt. Z. Path., 37, 118.

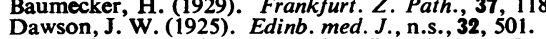

Ehnmark, E., and Jacobowsky, B. (1926). Upsala Läk. Fören. Fohr., 31, 565.

Foot, N. C., and Zeek, P. (1931). Amer. J. Path., 7, 605.

Forbes, W., and Maloney, A. F. J. (1950). J. Path. Bact., 62, 403.

King, A. B., Chambers, J. W., and Garey, J. (1952). Arch. Neurol. Psychiat. (Chicago), 68, 266.

Kissel, P., Rousseaux, R., Beau, A., Midon, J., and Arnould, G. (1950). Rev. neurol. (Paris), 82, 385. Mackay, F. H., and Hurteau, E. F. (1942). J. nerv. ment. Dis.,

Maximow, A. A., and Bloom, W. (1948). A Textbook of Histology, 5th ed., p. 224. Saunders, Philadelphia and London.

Pautler, E. E., and Gallavan, E. M. (1951). A.M.A. Arch. Path., 51, 238 .

Pol, R. (1905). In Festschrift für Professor Julius Arnold. Beitr. Path. Anat., Suppl. 7, p. 737. Ray, B. S., and Foot, N. C. (1940). Arch. Neurol. Psychiat. (Chicago),

Russi, S., Robinson, C., and Nagler, B. (1953). Sth. med. J. (Bgham, Ala.), 46, 336.



Touraine, A. (1949). Ann. Derm. Syph. (Paris), 8 ser., 9, 489.

Weimann, W. (1923). Z. ges. Neurol. Psychiat.,85, 508.

Willis, R. A. (1948). Pathology of Tumours, p. 914. Butterworth, London.

Winkelman, N. W., Gotten, N., and Silverstein, A. (1936). Arch. Neurol. Psychiat. (Chicago), 35, 919. 